\title{
К ИСТОРИИ СТАНОВЛЕНИЯ СОЦИАЛЬНОЙ ФИЛОСОФИИ ХХ ВЕКА: ВТОРАЯ ДИСКУССИЯ ОБ АЗИАТСКОМ СПОСОБЕ ПРОИЗВОДСТВА
}

\section{ON THE HISTORY OF THE FORMATION OF SOCIAL PHILOSOPHY OF THE XX CENTURY: THE SECOND DISCUSSION ABOUT THE ASIAN MODE OF PRODUCTION}

\section{Smetankina A. Ogarkov}

Summary: This article discusses the issues of the "Asian» mode of production, as a specific for a number of countries (not necessarily the East or Southeast Asia) economic structure (and not a formation), which retains its importance for a long time. For example, the traditions of a large family, with the unconditional authority of the head of the family, the strength of kinship ties, historical forms of economy (irrigated agriculture) are signs characteristic of the way of life of a number of countries that have freed themselves from colonial dependence.

Thus, the theory of socio-economic formations is able to successfully solve methodological difficulties in the process of explicating the content of the categories of the universal and the particular in historical analysis, provided that the formation typology remains open for deepening and expansion and is applied in a specific research situation.

Keywords: social philosophy, Asian mode of production, discussion, countries of the East, social contradictions.

\author{
Сметанкина Людмила Васильевна \\ д.ф.н., ФГКВОУ ВО «Военная орденов Жукова и Ленина \\ Краснознаменная академия связи имени Маршала \\ Советского Союза С.М. Буденного» Министерства \\ обороны Российской Федерации \\ Ismetankina.umo@mail.ru \\ Огарков Александр Николаевич \\ К.ф.н., дочент, ФГБОУ ВО «Санкт-Петербургская \\ государственная художественно-промышленная \\ академия имени А.Л. Штиглица» \\ suer53@inbox.ru
}

Аннотация: В данной статье рассмотрены вопросы 06 «азиатском» способе производства, как специфическом для ряда стран (необязательно Востока или Юго-Восточной Азии) экономическом укладе (а не формации), сохраняющем свое значение в течение длительного времени. Например, традиции большой семьи, с безусловным авторитетом главы семьи, крепость кровнородственных связей, исторические формы хозяйства (поливное земледелие) - признаки, характерные для уклада жизни ряда стран, освободившихся от колониальной зависимости.

Таким образом, теория общественно-экономических формаций способна с успехом разрешать методологические трудности в процессе экспликации содержания категорий всеобщего и особенного в историческом анализе при условии, что формационная типология остается открытой для углубления и расширения и применяется в конкретной ситуации исследования.

Ключевые слова: социальная философия, азиатский способ производства, дискуссия, страны Востока, общественные противоречия.

После драматической тридцатилетней паузы дискуссия об азиатском способе производства возобновилась с новой силой в 1964-1968 годах.

Особенность второй дискуссии - «втягивание в нее большого количества профессиональных историков, что способствовало уточнению теоретических позиций, значительно более широкая научная аудитория (в дискуссию включились Институт философии АН СССР, Институт истории АН СССР, Институт народов Азии и Африки АН СССР, журналы: «Вестник Древней истории», «Советская этнография», «Вопросы истории», «Вопросы философии», «Народы Азии и Африки», не считая отдельных выступлений и монографий).

Сразу выявилось отсутствие единства точек зрения представителей исторической и философской науки по вопросу о познавательных возможностях теории общественно-экономических формаций, как и отсутствие единого подхода представителей философской науки к 
методологическим проблемам связи формационного и внутри-формационного анализа истории, степени жесткости единой формационной линии, по вопросу определения формационного отношения или ведущего уклада формации. Формально же речь шла как в первом, так и во втором обсуждении о наличии или отсутствии в конкретных странах Средней Азии, Ближнего Востока, Африки (во втором диспуте) признаков «азиатского способа производства», и о причинах, побудивших К. Маркса поставить «азиатскую формацию» в общеформационный ряд. В частности, в первой дискуссии очень много внимания уделялось попыткам доказать случайность или временность употребления термина «азиатский способ производства» Марксом. Аргументы противников «азиатского способа производства» (и в первой, и во второй дискуссии) могут быть сведены к следующим тезисам:

1. недостаточность исторических сведений о развитии общины в Германии не позволили Марксу в свое время (до 1854 года) выявить признаки подобия азиатской и германской общины. После ознакомления с исследованием Г. Маурера о германской марке появились все основания для этого, и Маркс отказался и от термина «азиатский способ производства», и от концепции особой, азиатской формации (например, В.Н. Никифоров).

2. Маркс под «азиатским способом производства» имел в виду особенности рабовладения на Востоке, а отнюдь не особые производственные отношения (М. Кокин).

3. «Азиатский способ производства» не покрывается созданной к тому времени Марксом типологией ни по одному из ряда признаков (А. Поляков, И. Лурье).

4. Маркс ни до, ни после «Предисловия к критике политической экономии» не употреблял понятия «азиатского способа производства».

5. Перевод работы Маркса неточен, в оригинале «азиатские способы производства», т.е. азиатские особенности (А. Поляков). Но здесь следует различать формальную и содержательную часть аргументации. Разнообразие аргументов имело, как правило, одну исходную проблему: категориальное содержание понятия «общественно-экономическая формация» и что в исторической реальности ему соответствует. Историки при этом, как правило, не смущались, обнаруживая ситуацию «выхода» за пределы известного круга исторических фактов и делая неожиданные теоретические выводы. Например, в ходе обсуждения проблемы «азиатского способа производства» в 1931 году И. Плотников подчеркивал, что все противники азиатской формации - не историки, а социологи, и что именно Маркс, а не Плеханов, изобрел «географический» фактор, указывая в своих работах, что одна из причин, приведших к формированию капиталистических отношений - открытие Аме- рики (резкое оживление торговли, сбыта товаров, появление мирового рынка). Согласно И. Плотникову, в Европе наблюдалось две «вспышки», стимулирующие развитие капитализма - в Италии в XI-XII вв. из-за ее монополии на торговлю с Востоком, и в Англии, Испании, Франции после открытия морского пути через Африку. Противники концепции «азиатского способа производства», как правило, называют «эталонную» сумму признаков «азиатского способа производства»: 1) отсутствие частной собственности на землю; 2) общинная форма землевладения; 3) наличие ренты-налога, отчуждаемого общинниками непосредственно в фонд государства; 4) наличие деспотической власти; 5) отсутствие классов - и сравнивают эту сумму признаков с «эталонной» системой дефиниций; общее определение способа производства, производительных сил, признаки класса и т.д., не учитывая взаимозависимости социологической модели и исторического знания.

По свидетельству ряда исследователей, Маркс и Энгельс вообще избегали дефиниций, которые, ограничивая число признаков, упрощают и в ряде случаев искажают социологическую схему. Поэтому в текстах Маркса и Энгельса дефиниции практически отсутствуют, за исключением общефилософских. Представляется, что противники «азиатского способа производства» и в ходе первой, и в ходе второй дискуссии, приводя в качестве аргумента в пользу жесткой последовательности линейной схемы исторического процесса точность и незыблемость социологической конструкции, имели в виду под марксистским историческим методом то, что принято именовать «концепцией охватывающего закона» Поппера-Гемпеля. Как известно, объяснение на основе охватывающего закона - это дедукция из описания начальных условий и закона, выявляющего причинно-следственную связь между этими условиями. В выявлении причинноследственной связи между историческими событиями, согласно этой концепции, и состоит задача историка, а историческое объяснение, как и научное, содержит набор высказываний, фиксирующих появление определенных событий в определенных пространственно-временных условиях и некоторый набор универсальных гипотез, с условием, что и набор высказываний, и набор универсальных гипотез должны быть подтверждены эмпирическими данными; законы же общественных наук - частный случай естественнонаучных законов: «Общие законы имеют довольно аналогичные функции в истории и в естественных науках, они являются обязательным инструментом исторического исследования, они даже составляют общий базис различных процедур, которые обычно рассматриваются как характерные для социальных наук в противовес наукам естественным» [18, с. 231].

В научном объяснении противники «азиатского спо- 
соба производства» как раз и подразумевают дедукцию из набора исторических фактов, связанных социологической закономерностью. Между тем выяснилось (Гемпель это признавал), что структура исторического объяснения гораздо сложнее, чем элементарная дедукция. Объяснение «по Гемпелю», как правило, ничего, кроме трюизмов, не дает, поскольку историческое объяснение всегда содержит обобщение, только оно не эксплицируется. И дело, конечно, не просто в соблюдении условий дедуцирования, а в правильном выборе операционального отношения между социологической моделью, социально-философскими предпосылками исторического исследования и набором привлекаемых для доказательства фактов, причем для каждого конкретного случая. Поэтому применение общих законов в историографии сопряжено с очень большими трудностями: «Одно дело - голая «фиктивность», прикрытая либо хронологической последовательностью или грубым социологическим схематизмом, механически привязанными эмпирии, либо двумя этими приемами вместе взятыми. И другое дело - подлинно научное историческое описание, которое имеет сложную аналитико-синтетическую структуру...» $[8$, с.96].

Объяснение в рамках формационного анализа не есть дедукция из диалектического закона развития; оно содержит как модель развития, так и средства для реализации всеобщего закона исторически; кроме того, поскольку речь идет о гуманитарном знании, то исследование является реализацией классовой позиции автора, но при этом классовая оценка не должна упрощать схему анализа. Формационный анализ, таким образом, - и социально-философское исследование, и историческая работа, и классовая позиция.

Наблюдается еще одна трудность в процессе «соединения» всемирно-исторической схемы чередования формаций с моделями локального исторического развития: история ни одной страны не повторяет всемирной истории, ни одна формационная модель «не совпадает» с исторической реализацией формационного отношения. Отсюда воспроизводимые в ходе исторического анализа противоречия, когда ищется эмпирическая база формационного отношения. Формация является и типом социального организма, и ступенью развития, но моменты статики и динамики разводятся лишь в логике. Историческое же исследование имеет дело со «ставшими» структурами. Поэтому системный аспект исторического анализа, разрабатываемый в пределах теории общественно-экономических формаций, мог бы существенно облегчить задачи историка. Так, М.А. Барг в одной из своих ранних статей [2] предлагал рассматривать общество (объект исторического исследования) как субстрат функциональных, генетических и трансформационных связей. Такая модель представляет собой как бы наглядную историю собственного становления, и может рассматриваться как статичная (если абстрагироваться от временной координаты), или динамичная. В масштабах всей формации функциональная структура модели общества задается основными связями, а в своих подсистемах выступает модифицированной, то есть каждая структура (функциональная, генетическая и трансформационная) регулируется как законами формации, так и автономными. Генетическая структура общества и структура его развития с точки зрения будущего являются лишь противоположно направленными временными проекциями одной и той же функциональной структуры.

Что же касается проблемы соотношения социологического и исторического моделирования, то трудность здесь заключается в том, что вычленение связей есть поиски общего, а общее уже предполагает отбор особенного по определенным критериям. Круг замыкается. Социологический ряд оказывается оторванным от исторического, но только в том случае, когда формационная типология «закрывается» для обществ нестандартной структуры. Одним из предлагаемых в литературе вариантов решения проблемы является конструирование не обобщающего типа общества, которому приписываются все признаки всех членов группы подобия, а усредняющего, сосредоточивающего черты большинства [7].

В таком случае моделирующая сила типа не совпадает с суммой обществ стандартной и нестандартной реализации типа. Поскольку не разработаны подобно модели капиталистической общественно-экономической формации модели предшествующих формаций, анализ нестандартных типов, отклоняющихся от общей типологии, оказался крайне затруднен. В частности, крайне трудной оказалась проблема определения места и значения «азиатской» формации в схеме мировой истории. Взгляды Маркса на связь формационных моделей и на строение первичной формации менялись в зависимости от степени освоения исторического материала, что отмечается, например, в монографии А.И. Ципко [10]: углубление марксистской теории общественного развития шло по трем направлениям - анализ взаимовлияния базисных и надстроечных явлений, выяснение существа и содержания исторической преемственности между различными формациями в рамках определенной линии исторической эволюции, постановка вопроса о сосуществовании и дополнении различных механизмов воспроизводства общественной жизни. Здесь же отмечается, что состояние всей общественной системы как целостности зависит не только от экономической основы системы, то есть от отношения людей, связанных с распределением средств производства и присвоения его результатов. Существуют и другие отношения: если в первый период становления марксистской концепции Маркс и Энгельс отождествляли форму общества с формой производства, то исследование германской марки показало, что на ранних этапах исторического развития 
формы человеческой коллективности были не следствием, а предпосылкой различных форм производства сотрудничества [12, с. 462-463]. Значит, естественные «формы общности» могут тормозить прогресс материального производства.

Одним из многих позитивных следствий дискуссии об «азиатском способе производства» как раз и было обострение исследовательского интереса к анализу внутриформационных закономерностей. Если вначале подобный анализ ограничивался пределами общесистемного анализа, то впоследствии стал обогащаться выводами из анализа конкретного механизма переходного периода, и понятия «уклад» [5].

М.А. Барг [1] предлагал начинать анализ с выявления господствующего формационного отношения с последующим вычленением фаз становления этого отношения как системы, причем рассматривать эволюцию не одного элемента, а всей их совокупности. Смена подсистем функционирующей системы происходит не одновременно, как и смена фаз развития элементов подсистем, что определяется состоянием внешней для системы среды. Задачей историка является изучение именно трансформации системы, и здесь понятие общественно-экономической формации дает философское основание для анализа функционирующей структуры, ведь при переходе от одной фазы системы в другую видоизменяется иерархия всех элементов функционирующей системы, вся система связей, появляются новые, исчезают старые: «...Смена субординации сфер задает новые закономерности. Осмысление общества как сочленения элементов, связей и зависимостей внутри и между множеств самостоятельных систем - ...таково логическое содержание понятия структуры исторического исследования» [1, с. 92].

Позже [3] системный анализ связей формационной и исторической типологий усложняется введением в употребление понятий «регион», «этнос», «уклад», «системные и несистемные элементы формации». Историк определяет тормозящие и ускоряющие развитие господствующего способа производства факторы, отграничивает социологические и исторические аспекты понятия «формация» (социологический аспект - тип формации, исторический - разновидность каждого типа). Предлагается рассмотреть вариант всемирного развития, как ряда синхронных фаз в развитии группы стран. Особое внимание уделяется теперь выявлению несистемных элементов, порожденных самой формацией и определяющих новое формационное отношение (например, описание развития капиталистического уклада в рамках феодальной формации). Формационное отношение предлагается рассматривать прежде всего как региональное (пространственная определенность формационной разновидности), и еще конкретнее: как проявление формационного отношения в истории раз- личных стран региона.

Другое направление социально-философских исследований, развитие которого свидетельствовало о тяготении философского, социологического и исторического анализа к синтезу, представляли А.Я. Гуревич [5] и А.В. Гулыга [4].

Отмечается тот факт, что докапиталистические формации унифицированы способом производства гораздо меньше, чем капиталистическая, что они гетерогенны. Формационное отношение предполагает, например, поляризацию двух основных классов - производящего эксплуатируемого и эксплуатирующего. Но в реальной истории помимо «чистых» классов существует множество «прослоек» между ними. Например, в рабовладельческих обществах древней Греции и Рима это мелкие производители, скотоводы, ремесленники, люмпен-пролетарии. Чистых формаций также не бывает. Так, в средневековом феодальном обществе сохраняются остатки рабовладения, родоплеменной уклад варваров, община в ее модифицированном виде. Классического феодализма, под которым понимается синтез позднеримских порядков и социальных отношений варваров, тоже в истории не было, поскольку аллодиальная форма землевладения нигде до конца не была вытеснена феодом. «Носителем» нового формационного отношения стал средневековый город. Поэтому социологическая формационная схема в историческом исследовании должна применяться крайне осторожно, а любое социальное явление должно быть изучено как элемент относительно замкнутой культурно-этнической общности, выполняющей определенные функции по ее воспроизводству.

Кроме того, модификация способа производства определяется многими факторами духовной жизни: религией, историческими традициями, языком. В границах указанного направления внутриформационного анализа был сформулирован чрезвычайно важный вывод: механизм движения докапиталистических обществ не может быть сведен к одним экономическим категориям: «Одной лишь социально-экономической характеристики древнего или средневекового общества оказывается недостаточно для проникновения в их тайны. Требуется построение полной типологии общественных связей, принимавших экономическую, политическую, идеологическую и иные формы» [5, с. 129].

Другой вывод: строить общественную модель должна историческая наука, но только на стадии высокого развития социологического анализа. Можно констатировать, что факт расхождения линий социологического и исторического исследования был осознан как итог дискуссии об «азиатском способе производства», а направления совершенствования и сближения этих линий определены в ходе дискуссий. 
Поэтому есть смысл проследить за логикой и аргументами некоторых участников дискуссий. В докладе В.И. Никифорова, в частности, отмечалось, что нет смысла множить число формаций, когда не разработана теория переходных периодов. Например, классическое рабство является лишь историческим и логическим пределом противоречий общины. Было предложено именовать рабовладельческий строй «общинно-рабовладельческим». Представляется ценной мысль, что расширение или сужение формационного ряда само по себе не способно дать приращение качества социальнофилософского анализа докапиталистических формаций. Нужно историческое исследование признаков «азиатского способа производства», направление которому задал Маркс. В интересном сообщении Седова отмечалось, что свидетельством низкого уровня социологического анализа являются попытки растворить в формационной схеме любой фальсифицирующий формационные признаки факт, что диахронный формационный анализ совершенно уничтожил синхронный, исторический: «Так, внутри античной формации можно выделить общество, основанное на эксплуатации крестьян против городской общины, общество, основанное на личном труде свободных землевладельцев, основанное на рабском труде и латифундиях, и общество, где осуществлен переход к феодальным формам эксплуатации. Все это - разные структуры в синхронном плане, одна формация - в диахронном» [13, с. 52].

Это яркий пример сознательного противопоставления исторического знания, под которым в данном случае имеется в виду синхронно-функциональный анализ, и социологического моделирования (в данном случае - формационной линии прогресса). Но развитие марксистского социально-философского знания продемонстрировало как раз обратное: оно в своей развитой форме представляет собой сложную аналитико-синтетическую структуру. Идеализированные объекты теории структурируют историческое объяснение, а последнее всегда содержит социологическую модель как гипотезу, открытую для проверки.

Обсуждение показало, что и сторонники, и противники «азиатского способа производства» принимали формационную типологию в той ее гипертрофированной форме, в которой она существовала с 1934 года. Ни Маркс, ни Энгельс никогда и нигде не отстаивали ее незыблемости. Даже в знаменитом «Предисловии к критике политической экономии» сказано: «В общих чертах, азиатский, античный, феодальный и современный, буржуазный, способы производства можно обозначить, как прогрессивные эпохи экономической общественной формации» [9, с. 7]. Важно то, что эта схема с изменением уровня и качества исторических знаний дополняется, но не меняется радикально. Исторические факты этой схемы фальсифицировать не могут, так как она введена как схема членения всемирной истории, то есть как идеализированная типология. Идеализация же в данном случае - необходимое сокращение числа признаков, принимаемое за единицу модели, задача которой - фиксация целостного и непрерывного характера социального развития (в аспекте связи общих законов развития и форм их реализации). Историческая же типология может быть сколь угодно сложной, имея формационный ряд в качестве ряда моделирующих типов.

\section{ЛИТЕРАТУРА}

1. Барг М.А. Проблемы социальной истории в освещении современной западной медиевистики. - М.: Наука, 1973. - 230 с.

2. Барг М.А. Структурный анализ в историческом исследовании // Вопросы философии. - 1964, № 10. - С. 83-92.

3. Барг М.А. Учение об общественно-экономических формациях и конкретный анализ исторического процесса // Очерки методологии познания социальных явлений. - М., 1970. - С. 249-293.

4. Гулыга А.В. История как наука // Философские проблемы исторической науки. - М., 1969. - С. 7-50.

5. Гуревич А.Я. К дискуссии о докапиталистических общественных формациях: формация и уклад // Вопросы философии. 1968, № 2. - С. 118-129.

6. Гуревич А.Я. Об исторической закономерности. Философские проблемы исторической науки. - М., 1969. - С. 51-79.

7. Израитель В.Я. Проблемы формационного анализа общественного развития. - Горький: Волго-Вят. кн. изд-во, 1975. - 191 с. гл.1, § 4.

8. Киссель М.А. К изучению структуры исторического исследования // Проблемы методологии социального познания. - Л.: Изд-во ЛгУ, 1985. - С. 91-110.

9. Маркс К. К критике политической экономии. Предисловие //Маркс К., Энгельс Ф. Соч. - 2-е изд. - Т. 13. - С. 5-9.

10. Маркс К. Наброски ответа на письмо В.И. Засулич // Маркс К., Энгельс Ф. Соч. - 2-е изд. - Т. 19. И - С. 400-421.

11. Маркс К. Письмо Ф. Энгельсу. 2 июня 1853 г. // Маркс К., Энгельс Ф. Соч. - 2-е изд. - Т. 28. - С. 212-216.

12. Маркс К. Экономические рукописи 1857-І861 гг. Часть первая // Маркс К., Энгельс Ф. Соч. - 2-е изд. - Т. 46, ч. І. - С. 1-564.

13. Общее и особенное в историческом развитии стран Востока: Материалы дискуссии об общественных формациях на Востоке (Азиатский способ производства) / Редкол.: Г.Ф. Ким (отв. ред.), В.Н. Никифоров и др. - М.: Наука, 1966. - 248 с.

14. Сметанкина Л.В., Огарков А.Н. К истории становления социальной философии XX века: вокруг дискуссии об азиатском способе производства // Современная наука: актуальные проблемы теории и практики. Серия: Познание. -2021. -№07. -C. 84-88 D0I 10.37882/2500-3682.2021.07.12

15. Ципко А.И. Некоторые философские аспекты теории социализма. - М.: Наука, 1983. - 216 с./ 
16. Энгельс Ф. Марка // Маркс К., Энгельс Ф. Соч. - 2-е изд. - Т. 19. - С. $327-345$.

17. Энгельс Ф. Письмо К. Марксу. 6 июня 1853 г. // Маркс К., Энгельс Ф. Соч. - 2-е изд. - Т. 28. - С. 216-223.

18. Hempel C.G. Aspects of Scientific Explanation and other essays in the philosophy of science. - H.; L., 1966., c.231.

(c) Сметанкина Людмила Васильевна (Ismetankina.umo@mail.ru), Огарков Александр Николаевич (suer53@inbox.ru).

Журнал «Современная наука: актуальные проблемы теории и практики»

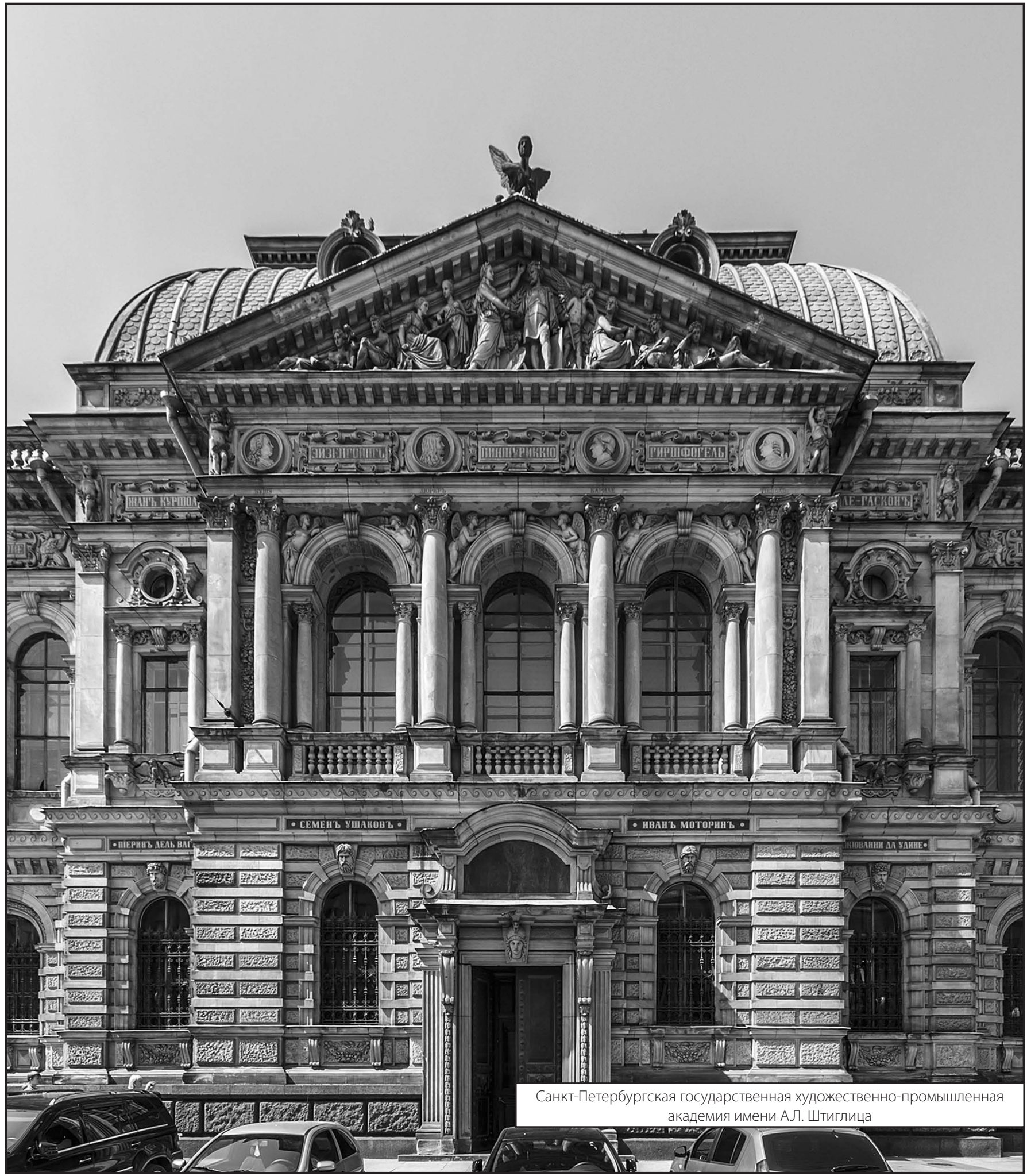

